\title{
Indoor environmental quality and the prevalence of childhood asthma and rhinitis in Wuhan area of China
}

\author{
ZHANG Ming ${ }^{1}$, ZHOU ESheng $^{2}$, YE Xin ${ }^{1}$, SUN YueXia ${ }^{3 *}$, SUNDELL Jan ${ }^{4} \&$ YANG Xu ${ }^{1 *}$ \\ ${ }^{1}$ Hubei Key Laboratory of Genetic Regulation and Integrative Biology, College of Life Sciences, Central China Normal University, Wuhan \\ 430079, China; \\ ${ }^{2}$ Department of Public Health, University Hospital, Central China Normal University, Wuhan 430079, China; \\ ${ }^{3}$ School of Environmental Science and Engineering, Tianjin University, Tianjin 300072, China; \\ ${ }^{4}$ Department of Building Science, Tsinghua University, Beijing 100081, China
}

Received October 15, 2012; accepted December 14, 2012; published online May 15, 2013

\begin{abstract}
Indoor environmental quality is suspected to be at least part of the cause of the increasing prevalence of childhood asthma and allergy. This study is part of the China, Children, Homes, Health $(\mathrm{CCHH})$ project, which was designed to identify the risk factors indoors that are associated with prevalence of asthma and allergy among children in China. A cross-sectional questionnaire study was carried out in Wuhan in 2011. The questionnaire was a modified (to Chinese building characteristics) version of a questionnaire used first in Sweden. The parents of 2193 children, aged 1-8 years, replied, a response rate of 91.4\% (2193/2400). Prevalences of asthma and allergic symptoms were calculated, and a Chi-square test and multiple logistic regression were used to identify risk factors. Prevalences of health outcomes are "wheezing last 12 months" 18.5\%, "cough at night last 12 months" $15.4 \%$, "doctor-diagnosed asthma" 6.0\%, "rhinitis last 12 months" 48.7\%, "doctor-diagnosed allergic rhinitis" 17.5\%. Factors associated with increased risk for asthma, allergy and related symptoms include living in an urban area, dampness (significant), use of gas for cooking, new dwelling decoration (paint and furniture obtained during pregnancy), keeping pets and breast feeding less than 3 months. Factors associated with reduced risk as installing an exhaust fan in the bathroom. Home environmental factors are significantly associated with the prevalence of childhood asthma and rhinitis in Wuhan. Urbanization and dampness problems at home are significant risk factors for doctor diagnosed asthma and allergic rhinitis among children in Wuhan.
\end{abstract}

children, asthma, rhinitis, home environment, indoor air quality, Wuhan area

Citation: Zhang M, Zhou E S, Ye X, et al. Indoor environmental quality and the prevalence of childhood asthma and rhinitis in Wuhan area of China. Chin Sci Bull, 2013, 58: 4223-4229, doi: 10.1007/s11434-013-5687-4

The International Study on Asthma and Allergies in Childhood (ISAAC), found that from 1992-2004, the prevalence of asthma and allergy increased dramatically among children 6-7 years in 56 countries/regions [1-3]. Genetic factors cannot explain this increase [4]. Since children spend $80 \%-90 \%$ of their time indoors, the indoor environment may be important. In earlier studies with the same design, it has been found that indoor pollution can induce asthma, allergic rhinitis, eczema, sick building syndrome, and other health effects [5-11], and also lead to more airways infec-

*Corresponding authors (email: yxiasun@gmail.com; yangxu@mail.ccnu.edu.cn) tions [12]. The results of epidemiological studies in China have also found that the prevalence of childhood asthma and allergic diseases has shown a rapid growth over time, but with location disparities [13,14].

In order to characterize the associations between the home environment and Chinese children's health, a national population-based project has been carried out in ten cities, including Wuhan. The present study is part of this CCHH study (China, Children, Homes, Health). Its main aim was to determine the prevalence of asthma and allergy illness among children in the Wuhan area, and to characterize the environmental risk factors that were associated with these 
diseases.

\section{Subjects and methods}

\subsection{Study subjects}

This questionnaire-based epidemiological investigation was carried out from April to May 2011 in the Wuhan area. Questionnaires were distributed to parents of 2400 children $1-8$ years old in kindergartens and primary schools. One randomly selected kindergarten and three primary schools were invited to join the study. On-site meetings were arranged among parents, school teachers and investigators to distribute questionnaires. Completed questionnaires were returned to school teachers. This study was approved by the Office of Scientific Research Management of Huazhong Normal University.

\subsection{Questionnaire}

The questionnaire used ISAAC study questions to determine the prevalence of asthma, allergy and related symptoms, and added Swedish DBH and the Bulgarian ALLHOME study questions [5,11] to ascertain indoor environmental characteristics. The added questions were modified slightly to adapt to Chinese homes. The original Swedish/Bulgarian questionnaire has also been used in Denmark, South Korea, Singapore, and USA $[9,15,16]$.

(i) Questions on children's asthma and allergies.

Questions on asthma and allergies are from ISAAC study [17].

(1) Asthma and related-symptoms:

Has your child ever had difficulty breathing, like wheezing sound?

In the last 12 months, has your child had wheezing or whistling in the chest?

In the last 12 months, has your child had a dry cough at night for more than two weeks?

Has your child been diagnosed with asthma by a doctor?

(2) Allergic rhinitis and related-symptoms:

Has your child had rhinitis ever, apart from a cough associated with a cold or the flu?

In the past 12 months, has your child had a problem with sneezing or a blocked nose when he/she did not have a cold or the flu?

Has your child been diagnosed with hay fever or allergic rhinitis by a doctor?

(ii) Questions on home environment exposure and life style.

(1) Building characteristics: residential location; surrounding environment; house type; house size; building age; house ownership; ventilation and heating system; window type; floor and wall covering; housing renovation before and after child was born. (2) Moisture related problems: visible mold or damp on walls, ceilings and floors; previous or present flooding; condensation on windowpane in winter; damp stains on clothing; perception of odors. (3) Life style related factors: breast feeding; daycare attendance; environmental tobacco smoke (ETS) among family members; pet keeping and pet avoidance; room cleaning and window opening (for ventilation) frequencies; home appliances; use of incense; children's outdoor activities.

\subsection{Data analysis}

The influence of building characteristics, dampness and life style on diagnosed asthma and allergic rhinitis were analyzed by $C h i$-square tests. Factors which reached significant levels in Chi-square test were used in binary logistic regression models with adjustment to gender, age and family allergic history (Model I). Then odds ratios of those factors which showed significant trends in Model I were calculated in multiple logistic regression models (Model II). All statistical analysis was performed with the SPSS 17.

\section{Results}

\subsection{Characteristics of investigated children}

Parents of 2193 children responded the questionnaire, giving a response rate of $91.4 \%$. Questionnaires were mostly filled out by mothers (64.6\%). Table 1 presents personal characteristics of 2193 children, including their ages, gender, length of being breastfed, and family allergic history.

Table 1 Personal characteristics of investigated children

\begin{tabular}{ll}
\hline \multicolumn{1}{c}{ Personal characteristics } & \multicolumn{1}{c}{ Number $(\%)$} \\
\hline Age & $123(5.6)$ \\
Less than 5 years old & $105(4.8)$ \\
5 years old & $226(10.3)$ \\
6 years old & $707(32.2)$ \\
7 years old & $1032(47.1)$ \\
8 years old & \\
Gender & $1156(52.7)$ \\
Male & $1037(47.3)$ \\
Female & \\
Breastfeeding period & $229(10.7)$ \\
Never & $101(4.7)$ \\
Less than 1 month & $111(5.2)$ \\
1-2 months & $357(16.6)$ \\
3-6 months & $1348(62.8)$ \\
More than 6 months & $126(5.7)$ \\
Family allergic history & \\
Paternal asthma & $54(2.5)$ \\
Paternal allergic rhinitis or eczema & $126(5.7)$ \\
Maternal asthma & \\
Maternal allergic rhinitis or eczema & \\
\hline & \\
\hline & \\
\hline
\end{tabular}




\subsection{Prevalence of asthma and allergies among investi- gated children}

Table 2 gives prevalences of asthma and allergies. The trend with increasing age is a decrease in asthma and rhinitis among children.

\subsection{Exposure factors}

Associations between building characteristics, dampness, life style and diagnosed asthma and rhinitis among children were analyzed by Chi-square tests, as shown in Tables 35. Living in an urban area, with gas as cooking fuel were strong risk factors for both diagnosed asthma and rhinitis. Living in an apartment, no exhaust fan in the bathroom were associated with diagnosed rhinitis. Building related moisture problems (dampness), especially visible mold, visible damp and condensation on windowpane in winter, were consistent risk factors for asthma and allergies (Table 4). Among life style factors, breastfeeding less than 3 months, pet keeping and use of incense were associated to a higher prevalence of asthma and rhinitis (Table 5).

\subsection{Logistic regression for children's asthma and allergic rhinitis}

Factors which had significant influence on health outcomes (Tables 3-5) in crude Chi-square test were analyzed in logistic regression models adjusted for gender, age and family allergic history, as shown in Tables 6 and 7. In Model I, an adjusted odds ratio for each variable was calculated separately, while in Model II odds ratios of variables were calculated in multiple logistic regression models.

\section{Discussions}

This paper presents a basic data set for the association of children's asthma and asthma related symptoms with home environmental factors in Wuhan. As in all cross-sectional studies, the results may be influenced by respondents' bias and unknown sources of confounding. The risk of bias, however, is reduced by the high response rate $(91 \%)$.

The $48.7 \%$ of parents reported that their children had rhinitis in the last 12 months. $31.2 \%$ of children had at least one asthmatic symptom, while $50.5 \%$ had at least one rhinitis symptom. These prevalences are as great or greater than those reported in traditional high prevalence countries such as the US [16]. This indicates that asthma and allergy problems among Wuhan children should be a public health priority.

Living in an urban area is a strong risk factor for diagnosed asthma and allergic rhinitis. Urbanization has been argued in previous studies to be a cause of the increase in asthma and allergy $[18,19]$. The causes of the Wuhan increase in asthma in appear to be associated with urbanization and the adoption of a modern "Westernized" lifestyle and their attendant environmental changes.

Among building characteristics, living in an apartment was a risk factor for diagnosed allergic rhinitis compared to living in a single family house. The finding that bigger, owned-by-occupant dwellings with exhaust fan in kitchens had more health problems among occupants was unexpected. After stratification by dwelling types, it was found that those characteristics had a co-linearity with the type of home. After adjustment for dwelling type, the strong associations between ownership and allergic rhinitis disappeared; while smaller houses became a risk factor for rhinitis. New furniture and wall repainting during pregnancy were related to a higher prevalence of asthma and allergic rhinitis, which indicates that early life is a crucial exposure period. Wood as a floor covering, however, was found to be a risk factor compared to cement (Tables 3 and 7). It is suspected that the glues for wood products may emit VOCs (volatile organic compounds), confounding the association between wood flooring and child's asthma and allergy. Further research, especially home inspection, is needed to explore this possibility.

Table 2 Prevalence of asthma and allergic rhinitis symptoms among the investigated children

\begin{tabular}{|c|c|c|c|c|c|c|c|}
\hline \multirow{2}{*}{ Symptoms } & \multirow{2}{*}{$\begin{array}{l}\text { Age adjusted } \\
\text { total, \% (n) }\end{array}$} & \multicolumn{6}{|c|}{ Stratified by the age of child, $\%(n)$} \\
\hline & & $<5$ years & 5 years & 6 years & 7 years & 8 years & $P^{\text {a) }}$ \\
\hline \multicolumn{8}{|l|}{ Asthma and related-symptoms } \\
\hline Wheeze in the last 12 months & $18.5(398)$ & $20.7(25)$ & $20.6(21)$ & $17.4(39)$ & $19.2(133)$ & $17.9(180)$ & 0.857 \\
\hline Cough at night last 12 months & $15.4(304)$ & $24.6(30)$ & $21.4(22)$ & $15.2(34)$ & $13.9(96)$ & $12.0(122)$ & 0.001 \\
\hline Doctor-diagnosed asthma & $6.0(128)$ & $9.9(12)$ & $7.9(8)$ & $6.8(15)$ & $6.2(43)$ & $4.9(50)$ & 0.173 \\
\hline \multicolumn{8}{|l|}{ Allergic rhinitis and related-symptoms } \\
\hline Rhinitis last 12 months & $48.7(956)$ & $59.3(73)$ & $57.7(60)$ & $43.6(98)$ & $44.4(307)$ & $41.1(418)$ & 0.000 \\
\hline Doctor-diagnosed rhinitis & $17.5(364)$ & $27.0(33)$ & $30.4(31)$ & $17.1(37)$ & $16.1(112)$ & $14.9(151)$ & 0.000 \\
\hline Any of the above-mentioned & $50.5(1014)$ & $59.8(73)$ & $62.7(64)$ & $44.9(98)$ & $49.0(335)$ & $44.4(445)$ & 0.000 \\
\hline
\end{tabular}

a) $P$ value in Pearson $C h i$-square test. 
Table 3 Impacts of building characteristics on children's asthma and allergic rhinitis

\begin{tabular}{|c|c|c|c|c|}
\hline \multirow[t]{2}{*}{ - } & \multicolumn{2}{|c|}{ Doctor-diagnosed asthma } & \multicolumn{2}{|c|}{ Doctor-diagnosed allergic rhinitis } \\
\hline & $\%(n)$ & $P^{\text {a) }}$ & $\%(n)$ & $P^{\text {a) }}$ \\
\hline \multicolumn{5}{|l|}{ Dwelling location } \\
\hline City & $7.3(112)$ & \multirow{2}{*}{0.000} & $19.4(298)$ & \multirow{2}{*}{0.000} \\
\hline Suburb and country & $2.6(16)$ & & $10.9(66)$ & \\
\hline \multicolumn{5}{|l|}{ Dwelling close to } \\
\hline highway (yes vs. no ) & $7.6(48)$ & 0.018 & $18.7(118)$ & 0.144 \\
\hline river/lake (yes vs. no) & $7.1(14)$ & 0.390 & $24.5(47)$ & 0.003 \\
\hline business area (yes vs. no) & $4.5(27)$ & 0.112 & $15.6(94)$ & 0.310 \\
\hline industrial area (yes vs. no) & $4.1(2)$ & 0.837 & $12.5(6)$ & 0.408 \\
\hline \multicolumn{5}{|l|}{ House type } \\
\hline Single and detached house & $5.1(38)$ & \multirow{2}{*}{0.154} & $13.8(103)$ & \multirow{2}{*}{0.000} \\
\hline Apartment & $6.7(76)$ & & $20.5(231)$ & \\
\hline \multicolumn{5}{|l|}{ House size } \\
\hline Less than $60 \mathrm{~m}^{2}$ & $7.8(23)$ & \multirow{3}{*}{0.359} & $13.6(40)$ & \multirow{3}{*}{0.000} \\
\hline $61-100 \mathrm{~m}^{2}$ & $5.6(52)$ & & $14.3(132)$ & \\
\hline More than $100 \mathrm{~m}^{2}$ & $5.8(52)$ & & $21.0(189)$ & \\
\hline \multicolumn{5}{|l|}{ House age } \\
\hline Less than 10 years & $5.2(56)$ & \multirow{2}{*}{0.208} & $17.6(188)$ & \multirow{2}{*}{0.536} \\
\hline More than 10 years & $6.5(67)$ & & $16.6(171)$ & \\
\hline \multicolumn{5}{|l|}{ Ownership } \\
\hline Yes & $6.3(91)$ & \multirow{2}{*}{0.485} & $18.2(261)$ & \multirow{2}{*}{0.027} \\
\hline No & $5.5(37)$ & & $14.3(94)$ & \\
\hline \multicolumn{5}{|l|}{ Exhaust fan in kitchen } \\
\hline Yes & $5.9(122)$ & \multirow{2}{*}{1.000} & $17.6(360)$ & \multirow{2}{*}{0.000} \\
\hline No & $5.7(4)$ & & $0(0)$ & \\
\hline Exhaust fan in bathroom & & & & \\
\hline Yes & $6.1(89)$ & & $12.5(82)$ & \\
\hline No & $5.9(39)$ & 0.812 & $19.2(279)$ & 0.000 \\
\hline Coal burning & & & & \\
\hline Yes & $5.2(3)$ & 1000 & $10.7(6)$ & 0270 \\
\hline No & $5.9(125)$ & 1.000 & $17.1(358)$ & \\
\hline Gas cooking & & & & \\
\hline Yes & $6.9(87)$ & 0010 & $20.7(259)$ & 0000 \\
\hline No & $4.5(41)$ & 0.019 & $11.7(105)$ & 0.000 \\
\hline Floor covering & & & & \\
\hline Wood board & $6.9(58)$ & & $22.0(183)$ & \\
\hline Plywood board & $6.4(30)$ & 0272 & $18.4(86)$ & 0000 \\
\hline Stone/tiles board & $4.9(22)$ & 0.272 & $11.5(52)$ & 0.000 \\
\hline Cement & $4.5(17)$ & & $10.4(39)$ & \\
\hline Furniture purchase & & & & \\
\hline Before pregnancy & $5.5(52)$ & & $15.6(146)$ & \\
\hline During pregnancy & $5.3(2)$ & 0908 & $18.4(7)$ & 0.312 \\
\hline In $0-1$ years old & $4.8(1)$ & 0.998 & $28.6(6)$ & 0.512 \\
\hline After 1 years old & $5.3(13)$ & & $18.4(45)$ & \\
\hline Room repaint & & & & \\
\hline Before pregnancy & $4.6(8)$ & & $18.0(31)$ & \\
\hline During pregnancy & $5.9(1)$ & & $29.4(5)$ & \\
\hline In $0-1$ years old & $5.9(1)$ & 0.902 & $29.4(5)$ & 0.512 \\
\hline After 1 years old & $6.4(12)$ & & $20.1(38)$ & \\
\hline
\end{tabular}

\footnotetext{
a) $P$ value in Pearson $C h i$-square test.
} 
Table 4 Impacts of moisture related factors on children's asthma and allergic rhinitis

\begin{tabular}{|c|c|c|c|c|}
\hline \multirow{2}{*}{ Exposure factors } & \multicolumn{2}{|c|}{ Doctor-diagnosed asthma } & \multicolumn{2}{|c|}{ Doctor-diagnosed allergic rhinitis } \\
\hline & $\%(n)$ & $P^{\mathrm{a})}$ & $\%(n)$ & $P^{\text {a) }}$ \\
\hline \multicolumn{5}{|l|}{ Visible mold } \\
\hline Yes & $12.2(17)$ & \multirow{2}{*}{0.001} & $23.9(33)$ & \multirow{2}{*}{0.024} \\
\hline No & $5.4(102)$ & & $16.4(310)$ & \\
\hline \multicolumn{5}{|l|}{ Visible damp } \\
\hline Yes & $5.2(93)$ & \multirow{2}{*}{0.003} & $21.3(49)$ & \multirow{2}{*}{0.052} \\
\hline No & $10.0(23)$ & & $16.2(290)$ & \\
\hline \multicolumn{5}{|l|}{ Flooding } \\
\hline Yes & $6.7(15)$ & \multirow{2}{*}{0.563} & $22.0(50)$ & \multirow{2}{*}{0.033} \\
\hline No & $5.7(101)$ & & $16.4(287)$ & \\
\hline \multicolumn{5}{|l|}{ Condensation } \\
\hline Yes, $\leqslant 5 \mathrm{~cm}$ & $5.2(66)$ & \multirow{2}{*}{0.004} & $15.3(194)$ & \multirow{2}{*}{0.000} \\
\hline$Y e s,>5 \mathrm{~cm}$ & $9.5(31)$ & & $24.3(79)$ & \\
\hline \multicolumn{5}{|l|}{ Damp stains on clothing } \\
\hline No & $5.4(69)$ & \multirow{2}{*}{0.134} & $15.8(200)$ & \multirow{2}{*}{0.123} \\
\hline Yes & $6.5(55)$ & & $18.4(156)$ & \\
\hline \multicolumn{5}{|l|}{ Stuffy smell often } \\
\hline No & $5.3(62)$ & \multirow{2}{*}{0.069} & $15.9(184)$ & \multirow{2}{*}{0.186} \\
\hline Yes & $7.3(61)$ & & $18.2(151)$ & \\
\hline \multicolumn{5}{|l|}{ Moldy/earthy smell often } \\
\hline No & $5.9(94)$ & \multirow{2}{*}{0.586} & $16.7(266)$ & \multirow{2}{*}{0.762} \\
\hline Yes & $6.6(23)$ & & $16.0(55)$ & \\
\hline
\end{tabular}

a) $P$ value in Pearson $C h i$-square test.

Table 5 Impacts of life style related factors on children's asthma and allergic rhinitis

\begin{tabular}{|c|c|c|c|c|}
\hline \multirow{2}{*}{ Exposure factors } & \multicolumn{2}{|c|}{ Doctor-diagnosed asthma } & \multicolumn{2}{|c|}{ Doctor-diagnosed allergic rhinitis } \\
\hline & $\%(n)$ & $P^{\text {a) }}$ & $\%(n)$ & $P^{\text {a) }}$ \\
\hline \multicolumn{5}{|l|}{ Breast feeding } \\
\hline Less than 3 months & $7.0(39)$ & \multirow{2}{*}{0.269} & $20.9(117)$ & \multirow{2}{*}{0.004} \\
\hline More than 3 months & $5.6(75)$ & & $15.4(204)$ & \\
\hline \multicolumn{5}{|l|}{ ETS } \\
\hline Yes & $5.5(68)$ & \multirow{2}{*}{0.278} & $16.0(196)$ & \multirow{2}{*}{0.145} \\
\hline No & $6.6(59)$ & & $18.4(163)$ & \\
\hline \multicolumn{5}{|l|}{ Pets keeping } \\
\hline Yes & $6.1(25)$ & \multirow{2}{*}{0.927} & $21.6(88)$ & \multirow{2}{*}{0.006} \\
\hline No & $6.0(103)$ & & $15.9(272)$ & \\
\hline \multicolumn{5}{|l|}{ Use of incense } \\
\hline Often & $14.3(9)$ & \multirow{2}{*}{0.004} & $19.0(12)$ & \multirow{2}{*}{0.657} \\
\hline Sometimes/never & $5.7(114)$ & & $16.9(338)$ & \\
\hline \multicolumn{5}{|l|}{ Home cockroach } \\
\hline Always/often & $10.1(17)$ & \multirow{2}{*}{0.017} & $19.3(32)$ & \multirow{2}{*}{0.373} \\
\hline Sometimes/never & $5.6(100)$ & & $16.6(297)$ & \\
\hline \multicolumn{5}{|l|}{ Home mice and/or rats } \\
\hline Always/often & $8.4(7)$ & \multirow{2}{*}{0276} & $16.9(14)$ & \multirow{2}{*}{0.990} \\
\hline Sometimes/never & $5.6(101)$ & & $16.8(303)$ & \\
\hline \multicolumn{5}{|l|}{ Home mosquitoes and flies } \\
\hline Always/often & $6.4(34)$ & \multirow{2}{*}{0.658} & $17.8(95)$ & \multirow{2}{*}{0.566} \\
\hline Sometimes/never & $5.8(92)$ & & $16.7(262)$ & \\
\hline \multicolumn{5}{|l|}{ Put bed sheets under sunshine } \\
\hline Often & $5.5(91)$ & \multirow{2}{*}{0.096} & $17.1(281)$ & \multirow{2}{*}{0.825} \\
\hline Sometimes/never & $7.5(36)$ & & $16.6(80)$ & \\
\hline \multicolumn{5}{|l|}{ Cleaning frequency } \\
\hline Less than once per week & $10.3(11)$ & \multirow{2}{*}{0.058} & $19.2(20)$ & \multirow{2}{*}{0.553} \\
\hline More than once per week & $5.8(117)$ & & $17.0(341)$ & \\
\hline
\end{tabular}

a) $P$ value in Pearson $C h i$-square test. 
Table 6 Risk factors on children's diagnosed asthma

\begin{tabular}{lcr}
\hline \multicolumn{1}{c}{ Exposure factors } & \multicolumn{2}{c}{ Doctor-diagnosed Asthma (AOR (95\% CI)) } \\
\cline { 2 - 3 } & \multicolumn{1}{c}{ Model I* } \\
\hline Dwelling location urban (ref: suburban/country) & $2.35(1.36,4.07)$ & $2.91(1.55,5.45)$ \\
Dwelling close to highway (ref: no) & $1.31(0.88,1.95)$ & $1.51(0.72,3.17)$ \\
Gas cooking (ref: no) & $1.44(0.97,2.14)$ & $1.90(1.01,3.56)$ \\
Visible mold (ref: no) & $2.09(1.17,3.75)$ & $2.04(0.87,4.77)$ \\
Visible damp (ref: no) & $2.00(1.21,3.29)$ & $1.50(0.94,2.40)$ \\
Condensation $>5$ cm (ref: $<5$ cm) & $2.24(1.05,4.78)$ & $1.40(0.79,2.47)$ \\
Use of incense often (ref: sometimes/never) & \\
Homeof cockroach often (ref: sometimes/never) & \\
\hline
\end{tabular}

* Model I: Odds ratios of each variable calculated separately with adjustment for gender, age and family allergic history; ** Model II: Odds ratios of dwellings location, visible mold, visible damp and use of incense in multiple logistic regression models adjusted for gender, age and family allergic history.

Table 7 Risk factors on children's diagnosed allergic rhinitis

\begin{tabular}{|c|c|c|c|}
\hline \multirow{2}{*}{\multicolumn{2}{|c|}{ Exposure factors }} & \multicolumn{2}{|c|}{ Doctor-diagnosed allergic rhinitis (AOR $(95 \% \mathrm{CI})$ ) } \\
\hline & & Model I* & Model II ** \\
\hline \multicolumn{2}{|c|}{ Dwelling location urban (ref: suburban/country) } & $1.73(1.28,2.35)$ & $1.51(0.85,2.69)$ \\
\hline \multicolumn{2}{|c|}{ Dwelling close to river/lake (ref: no) } & $1.55(1.06,2.25)$ & $1.13(0.63,2.01)$ \\
\hline \multicolumn{2}{|c|}{ House type: apartment (ref: single family house) } & $1.53(1.16,2.00)$ & $1.57(0.99,2.49)$ \\
\hline \multirow{3}{*}{ House size $\left(\mathrm{m}^{2}\right)$} & More than 100 & 1.00 & 1.00 \\
\hline & Less than 60 & $0.60(0.40,0.89)$ & $0.97(0.43,2.17)$ \\
\hline & $61-100$ & $0.67(0.51,0.86)$ & $1.09(0.48,2.48)$ \\
\hline \multicolumn{2}{|c|}{ Owner of dwelling (ref: rent dwelling) } & $1.40(1.06,1.87)$ & $1.21(0.71,2.05)$ \\
\hline \multicolumn{2}{|c|}{ No exhaust fan in bathroom (ref: fan in room) } & $1.57(1.18,2.08)$ & $1.33(0.76,2.32)$ \\
\hline \multicolumn{2}{|c|}{ Gas cooking (ref: no) } & $1.84(1.42,2.39)$ & $1.35(0.83,2.19)$ \\
\hline \multirow{4}{*}{ Floor covering } & Cement & 1.00 & \\
\hline & Wood board & $2.31(1.56,3.41)$ & $1.37(0.74,2.55)$ \\
\hline & Plywood board & $1.48(0.95,2.28)$ & \\
\hline & Stone/tiles board & $1.05(0.66,1.57)$ & \\
\hline \multicolumn{2}{|c|}{ Visible mold (ref: no) } & $1.39(0.89,2.18)$ & \\
\hline \multicolumn{2}{|c|}{ Flooding (ref: no) } & $1.19(0.82,1.71)$ & \\
\hline \multicolumn{2}{|c|}{ Condensation (ref: $<5 \mathrm{~cm}$ ) } & $1.53(1.12,2.11)$ & $1.42(1.01,2.00)$ \\
\hline \multicolumn{2}{|c|}{ Breastfeeding $>3$ months (ref: $<3$ months) } & $1.24(0.94,1.63)$ & \\
\hline \multicolumn{2}{|c|}{ ETS (ref: no) } & $0.99(0.80,1.22)$ & \\
\hline \multicolumn{2}{|c|}{ Pets keeping (ref: no) } & $1.60(1.20,2.13)$ & $1.67(0.99,2.81)$ \\
\hline
\end{tabular}

* Model I: Odds ratios of each variable in binary logistic regression models with adjustment to gender, age and family allergic history; ** Model II: Calculation of adjusted odds ratios in multiple logistic regression models of variables which reached significant level in model I.

Dampness problems in the Wuhan area are serious and signs of dampness, especially the index of visible dampness and condensation on windowpane in winter, were strong and significant risk factors for asthma and allergy. This finding is consistent with previous international parallel studies carried out in regions with different climates [5,11, 12]. Condensation on window panes in winter is a proxy for poor ventilation [20]. Humid air condenses on cold surfaces such as walls and ceilings when extra moisture cannot be removed from the room, perhaps due to a lower air change rate. We found that behaviors or life styles that reduce dampness problems, for example installing exhaust fan in bathrooms, were associated with less asthma and allergic rhinitis among children in Wuhan. The association of air change rate in Wuhan dwellings with health outcomes of children shall be studied in the next step.

Among life style factors, breast feeding for less than 3 months, pet keeping at home and use of incense were related to a higher prevalence of asthma and allergic rhinitis. These findings are consistent with previous global children and home studies in Europe, America and Asia [21,22].

In conclusion, asthma in Wuhan children poses challenges for planners, architects, health services, and researchers to respond to the growing burden of asthma disability, 
especially among urban populations. Urbanization, and dampness problems are strong risk factors for diagnosed asthma and allergic rhinitis among children in Wuhan area.

This work was supported by the National Natural Science Foundation of China (51076079, 51136002) and National Key Technologies R\&D Program of China (2012BAJ02B03). We are grateful to Professor Yinping Zhang of the Department of Building Science, Tsinghua University and Professor Baizhan Li of the Faculty of Architecture and Urban Planning, Chongqing University for their excellent suggestions and comments on this work. We appreciate Louise B. Weschler for her modification on this manuscript.

1 Asher M I, Montefort S, Bjorksten B, et al. Worldwide time trends in the prevalence of symptoms of asthma, allergic rhinoconjunctivitis, and eczema in childhood: ISAAC phases one and three repeat multicountry cross-sectional surveys. Lancet, 2006, 368: 733-743

2 Ait-Khaled N, Pearce N, Anderson H R, et al. Global map of the prevalence of symptoms of rhinoconjunctivitis in children: The International Study of Asthma and allergies in Childhood (ISAAC) Phase Three. Allergy, 2009, 64: 123-148

3 Lai C K, Beasley R, Crane J, et a1. Global variation in the prevalence and severity of asthma symptoms: Phase three of the international study of asthma and allergies in childhood (ISAAC). Thorax, 2009, 64: 476-483

4 Wong G W, Chow C M. Childhood asthma epidemiology: Insights from comparative studies of rural and urban populations. Pediatr Pulm, 2008, 43: 107-116

5 Bornehag C G, Sundell J, Hagerhed-Engman L, et al. 'Dampness' at home and its association with airway, nose, and skin symptoms among 10851 preschool children in Sweden: A cross sectional study. Indoor Air, 2005, 15(Suppl 10): 48-55

6 Bornehag C G, Sundell J, Weschler C J, et al. The association between asthma and allergic symptoms in children and phthalates in house dust: A nested case-control study. Environ Health Persp, 2004, 112: 1393-1397

7 Bornehag C G, Sundell J, Hagerhed-Engman L, et al. Association between ventilation rates in 390 Swedish homes and allergic symptoms in children. Indoor Air, 2005, 15: 275-280

8 Choi H, Schmidbauer N, Sundell J, et al. Common household chemicals and the allergy risks in pre-school age children. PLoS One, 2010,
5: e13423

9 Hsu N Y, Lee C C, Wang J Y, et al. Predicted risk of childhood allergy, asthma, and reported symptoms using measured phthalate exposure in dust and urine. Indoor Air, 2012, 22: 186-199

10 Kolarik B, Naydenov K, Larsson M, et al. The association between phthalates in dust and allergic diseases among Bulgarian children. Environ Health Persp, 2008, 116: 98-103

11 Naydenov K, Popov T, Mustakov T, et al. The association of pet keeping at home with symptoms in airways, nose and skin among Bulgarian children. Pediatr Allergy Immunol, 2008, 19: 702-708

12 Sun Y, Zhang Y, Sundell J, et al. Dampness at dorm and its associations with allergy and airways infection among college students in China: A cross-sectional study. Indoor Air, 2009, 19: 174-182

13 Lu H B, Deng F R, Sun J D, et al. The comparison of the indoor environmental factors associated with asthma and related allergies among school-child between urban and suburban arefs in Beijing (in Chinese). Chin J Prev Med, 2010, 44: 626-630

14 Wang S L, Guo X B, Zhang J L. Study on the effects of ambient air pollution on respiratory disease and symptoms among school-age children in Beijing (in Chinese). J Environ Health, 2004, 21: 41-44

15 Tham K W, Zuraimi M S, Koh D, et al. Associations between home dampness and presence of molds with asthma and allergic symptoms among young children in the tropics. Pediatr Allergy Immunol, 2007, 18: $418-424$

16 Sun Y, Sundell J. Life style and home environment are associated with racial disparities of asthma and allergy in Northeast Texas children. Sci Total Environ, 2011, 409: 4229-4234

17 Asher M I, Keil U, Anderson H R, et al. International study of asthma and allergies in childhood (ISAAC): Rationale and methods. Eur Respir J, 1995, 8: 483-491

18 Cooper P J, Rodrigues L C, Cruz A A, et al. Asthma in Latin America: A public health challenge and research opportunity. Allergy, 2009, 64: 5-17

19 Aligne C A, Auinger P, Byrd R S, et al. Risk factors for pediatric asthma. Am J Respir Crit Care Med, 2000, 162: 873-877

20 Sun Y, Zhang Y, Bao L, et al. Ventilation and dampness in dorms and their associations with allergy among college students in China: A case-control study. Indoor Air, 2011, 21: 277-283

21 Hagerhed-Engman L, Bornehag C G, Sundell J, et al. Day-care attendance and increased risk for respiratory and allergic symptoms in preschool age. Allergy, 2006, 61: 447-453

22 Hsu N Y, Wu P C, Bornehag C G, et al. Feeding bottles usage and the prevalence of childhood allergy and asthma. Clin Dev Immunol, 2012, doi: 10.1155/2012/158248

Open Access This article is distributed under the terms of the Creative Commons Attribution License which permits any use, distribution, and reproduction in any medium, provided the original author(s) and source are credited. 